\title{
Hierarchical genetic structure and effective population sizes in Phalacrus substriatus
}

\author{
PÄR K. INGVARSSON $\dagger^{*} \&$ KATARINA OLSSON $\ddagger$ \\ $\dagger$ †epartment of Ecological Botany and †Department of Genetics, University of Umeå, S-901 87 Umeå, Sweden
}

\begin{abstract}
In this paper we present an analysis of the hierarchical population structure of the mycophagous beetle Phalacrus substriatus. The analysis showed that $P$. substriatus is substructured at both hierarchical levels studied, among islands and among local populations within islands. The level of differentiation among local populations was about three times as high as among different islands ( $F_{\mathrm{PL}}=0.043$ and $F_{\mathrm{LT}}=0.013$, respectively). This stands in marked contrast to the patterns expected, based on the dispersal of $P$. substriatus, as the average dispersal distance of individual beetles is less than a metre per generation. Several explanations are discussed which can explain the observed patterns. We also estimated the effective population size for both hierarchical levels. The results show that the $N_{\mathrm{e}} / N$ ratios are well below unity, both for local populations and for islands. The average $N_{\mathrm{e}} / N$ ratio for local populations was only 0.210 (geometric mean, 0.172), whereas for islands the observed $N_{\mathrm{e}} / N$ ratios ranged from 0.75 to 0.98. Population subdivision is expected to increase the global (island) effective population size under equilibrium situations. However, random extinctions and recolonizations can lead to significant reductions in the global effective population size. Because population turnover is a commonly occurring phenomenon in $P$. substriatus, we argue that this is, at least partly, responsible for the low $N_{\mathrm{e}} / N$ ratios observed in this species. The low effective population sizes, both for local populations and for islands, will result in rapid erosion of a large proportion of the genetic variation present. The present study thus highlights the need to take random processes, such as extinction-recolonization dynamics, into account when studying effects of spatial subdivision.
\end{abstract}

Keywords: effective population size, extinction, gene flow, genetic drift, population structure, recolonization.

\section{Introduction}

Over the last few decades it has been recognized that many species are naturally subdivided into discrete patches, for instance because of discontinuous habitat distributions or limited dispersal capabilities (Roderick, 1996). The geographical structure of local populations is an integral part of the ecology of a species and combines both demographic and genetic processes, such as gene flow, genetic drift and selection (Slatkin, 1987). Detailed knowledge about how genetic variation is structured within and among different populations is crucial for a full understanding of the evolutionary dynamics of a species. Moreover, populations can be subdivided at several hierarchical levels and, depending on the scale of study, different processes may be of importance in determining the observed patterns of popu-

Correspondence. E-mail: pelle@ekbot.umn.se lation differentiation (Slatkin, 1987). For instance, as distance between populations increases, gene flow is expected to become less effective in causing genetic cohesion among populations, because drift and adaptation to local conditions, both factors which increase differentiation among populations, are inversely related to gene flow (Slatkin, 1985, 1987). The actual levels of gene flow among the units at a certain hierarchical level of population structure determine whether they will be bound together into one evolutionary unit or if they will assume more independent evolutionary trajectories (Slatkin, 1987).

Another important evolutionary property is the variance effective population size, $N_{\mathrm{e}}$. This is the size of an ideal population undergoing the same rate of change in the genetic variance per generation as the studied population (Crow \& Kimura, 1970). Even though the effective population size is an 
important property, $N_{\mathrm{e}}$ is seldom estimated in natural populations because it is notoriously difficult to compute accurately (see Nunney, 1995, for a recent discussion about estimating $N_{\mathrm{e}}$ using demographic and genetic methods). Moreover, the effective size is influenced by population subdivision (Chesser et al., 1993; Whitlock \& Barton, 1997) and consequently the effective population size will also be affected by the scale at which it is measured. Detailed knowledge of the effective population size is of importance in determining whether observed levels of genetic differentiation can be attributed solely to genetic drift or whether other scenarios, such as selection, must be invoked.

In this paper we present a hierarchical analysis of the population structure of the mycophagous beetle Phalacrus substriatus. An earlier study focused on the population structure of $P$. substriatus over a small spatial scale $\left(<1000 \mathrm{~m}^{2}\right)$, corresponding roughly to a single population of the host plant Carex nigra (Ingvarsson et al., 1997). In that study we found evidence for a strong degree of differentiation among local $P$. substriatus populations, separated by only a few metres. We also found that recurrent extinctions and recolonizations led to a significant increase in the levels of differentiation. In this paper we extend the analysis of the population structure of $P$. substriatus to include two more island populations of the host plant $C$. nigra. We use $F$-statistics (Wright, 1951) to partition the genetic differentiation among the different levels in the hierarchy (within populations, among populations and among islands). We further provide estimates of the effective population sizes, both at the population and island level. The results are discussed in the context of the balance between gene flow and random processes in shaping the population structure of $P$. substriatus.

\section{Study organism}

Phalacrus substriatus Gyll. (Phalacridae, Coleoptera) is mycophagous, like most of the beetles in the family Phalacridae (Steiner, 1984). The adults are small $(1.0-2.0 \mathrm{~mm})$, shiny black and can be found on plants of various Carex species at the onset of flowering in early June. The adults feed on overwintering teliospores and germinating basidiospores of smut fungi of the genus Anthracoidea (Ustilaginales) and on Carex pollen. Adult beetles are active for approximately 3 weeks. The female lays eggs either on the surface of or in a hole bitten in the perigynium. Larvae hatch after approximately 1 week and feed in the developing smut sori (Kontka- nen, 1936). The larval period lasts 3-4 weeks, after which pupation occurs in the sorus. Adult beetles emerge after 3 weeks and appear to overwinter as adults at the base of the tussock (Kontkanen, 1936; P.K. Ingvarsson, personal observation). Phalacrus substriatus is univoltine in the study area and there is no overlap between parent and offspring generations because all adult beetles die before larval pupation occurs (P.K. Ingvarsson, personal observation). In the study area $P$. substriatus feeds exclusively on Anthracoidea heterospora Kukk. infecting florets of the sedge Carex nigra (var. recta). Carex nigra var. recta forms dense tussocks, which occur as discrete, easily identified patches on the shores on the studied islands.

\section{Materials and methods}

\section{Sampling of beetles}

The study was carried out on three islands in the Skeppsvik archipelago $\left(63^{\circ} 44-48^{\prime} \mathrm{N}, 20^{\circ} 31-33^{\prime} \mathrm{E}\right)$ outside Umeå, northern Sweden (for a general description of this area see Ericson, 1981). In 1994 five different tussocks of the host plant $C$. nigra were sweep-netted on the different islands in the archipelago. Only five tussocks were included because the sampling was part of a pilot study to determine the population structure of $P$. substriatus. All $P$. substriatus beetles found when sweep-netting the tussocks were collected, stored in Eppendorf tubes and brought back to the lab. where they were sexed and subsequently frozen alive at $-70^{\circ} \mathrm{C}$. The sweepnetting was repeated four times over a period of 2 weeks to sample as high a proportion of beetles in each tussock as possible. In 1995 the sweep-netting procedure was increased to include between 40 and 48 tussocks on the same islands as sampled in 1994. The sweep-netting procedure followed the same outline as in 1994 and all tussocks sampled in 1994 were also sampled in 1995. The average distance between sampled tussocks was $\approx 1 \mathrm{~m}$ and the average distance between the three different islands was $c .300 \mathrm{~m}$. In this paper all beetles found within a tussock will be referred to as a local $P$. substriatus population, and all local populations found on a single island will be referred to as an island population of $P$. substriatus.

\section{Electrophoretic techniques}

Sampled beetles were stored in Eppendorf tubes at $-70^{\circ} \mathrm{C}$ until they could be processed for electrophoresis. Five different enzyme systems were 
analysed: acotinate hydratase (Acn), isocitrate dehydrogenase (Idh), malate dehydrogenase (Mdh), phosphoglucoisomerase (Pgi), and triose-phosphate isomerase (Tpi). Each whole beetle was ground in $15 \mu \mathrm{L}$ distilled water and the enzymes were resolved on a 12 per cent starch gel made from a 14:1 dilution of a Tris-citrate buffer ( $\mathrm{pH} 7.0)$. After staining, alleles were scored and the population genetic structure was estimated by use of $F$-statistics (Wright, 1951). For a more detailed description of the electrophoretic techniques see Ingvarsson et al. (1997).

\section{Analysis of population structure}

\section{Estimation of hierarchical F-statistics}

The $F$-statistics were calculated using the Weir \& Cockerham (1984) estimators, following the threelevel hierarchical method outlined in Weir (1990, pp. 156-159). The hierarchical analysis of gene frequencies was performed using the statistical package SAS (1990). Following the methods in Weir (1990), variance components for within individuals, $\sigma_{\mathrm{w}}^{2}$, among individuals within populations, $\sigma_{\mathrm{i}}^{2}$, among local populations within islands, $\sigma_{\mathrm{p}}^{2}$, and among islands, $\sigma_{1}^{2}$, were calculated from the corresponding mean squares and correction terms. Hierarchical $F$-statistics were then estimated from these variance components as follows: genetic differentiation among individuals within the total sample, $F_{\mathrm{IT}}=\left(\sigma_{\mathrm{i}}^{2}+\sigma_{\mathrm{p}}^{2}+\sigma_{\mathrm{l}}^{2}\right) /\left(\sigma_{\mathrm{w}}^{2}+\sigma_{\mathrm{i}}^{2}+\sigma_{\mathrm{p}}^{2}+\sigma_{\mathrm{l}}^{2}\right)$, nonrandom mating within populations, $\left(F_{\mathrm{IP}}=\sigma_{\mathrm{i}}^{2} /\left(\sigma_{\mathrm{w}}^{2}+\sigma_{\mathrm{i}}^{2}\right)\right.$, differentiation among populations within islands, $F_{\mathrm{PL}}=\sigma_{\mathrm{p}}^{2} /\left(\sigma_{\mathrm{w}}^{2}+\sigma_{\mathrm{i}}^{2}+\sigma_{\mathrm{p}}^{2}\right)$, and differentiation among islands, $F_{\mathrm{LT}}=\sigma_{1}^{2} /\left(\sigma_{\mathrm{w}}^{2}+\sigma_{\mathrm{i}}^{2}+\sigma_{\mathrm{p}}^{2}+\sigma_{1}^{2}\right)$. These statistics are related by the equation:

$\left(1-F_{\mathrm{IT}}\right)=\left(1-F_{\mathrm{IP}}\right)\left(1-F_{\mathrm{PL}}\right)\left(1-F_{\mathrm{LT}}\right)$.

Information from multiple alleles and multiple loci was combined according to the suggestions of Weir \& Cockerham (1984), and the variances of the estimates were obtained using jackknifed procedures over alleles and loci (Weir \& Cockerham, 1984; Weir, 1990; Goudet, 1993). Because the estimators are corrected for sample size differences, slightly negative values of $F_{\mathrm{PL}}$ and $F_{\mathrm{LT}}$ can occur. These negative values should be interpreted as indicating no genetic differentiation. To test whether a particular $F$-statistic was significantly different from zero we calculated one-tailed 95 per cent confidence intervals (CI) for the different statistics (two-tailed CIs for $F_{\mathrm{IT}}$ and $F_{\mathrm{IS}}$ ) and determined whether they showed any overlap with zero. Each CI was esti- mated by bootstrapping over loci 1500 times. The bootstrap analyses were performed using the program FSTAT v.1.2 (Goudet, 1995).

\section{Effective size of local populations, $\mathrm{N}_{e(p)}$}

We estimated the effective population size of local $P$. substriatus populations using the method devised by Waples (1989). Waples developed a general model for determining the effective population size of a population from temporal changes in allele frequencies. The method assumes that the variation is neutral (or nearly so) and that migration among subpopulations is negligible. The error in estimating effective population size in the presence of migration is proportional both to the migration rate but also to the time separating the two sample events (Nei \& Tajima, 1981). How gene flow among populations influences the estimation of effective population size depends both on average gene frequency in migrants and in individuals within the population receiving the migrants. The migration rate among local $P$. substriatus populations is far from negligible ( $m=0.366$; Ingvarsson et al., 1997), so the estimate of the effective population size is clearly going to be affected by migration from surrounding populations. Omitting the effects of migration when estimating the effective population size ignores an important source of gene frequency change. However, migration acts as a constraining force on gene frequency change by genetic drift and ignoring migration will consequently lead to $N_{e}$ estimates that are too high. There are currently no methods that explicitly take migration into account when estimating effective population sizes from the temporal change in allele frequencies.

There are two different formulae for calculating $N_{\text {e(p) }}$, depending on whether individuals are sampled before or after reproduction (Waples, 1989; eqns 11 and 12). In the present study, beetles were sampled at the end of the reproductive period, so Method I of Waples (1989) is more appropriate. With this sampling method the effective population size, $N_{\text {e(p) }}$ is estimated as:

$N_{\mathrm{e}(\mathrm{p})}=\frac{t}{\left(2 \hat{F}_{\mathrm{c}}-1 / S_{0}-1 / S_{t}+2 / N_{\mathrm{c}}\right)}$,

where $t$ is the time between the two sampling events, $S_{0}$ and $S_{t}$ are the respective sampling sizes at the two sampling events and $N_{\mathrm{c}}$ is the population size at time 0 (the first sampling period). $\hat{F}_{c}$ is the weighted, standardized variance in allele frequencies (Waples, 1989; Goudet, 1993), 


$$
\hat{F}_{\mathrm{c}}=\frac{\sum_{i=1}^{k}\left(x_{i}-y_{i}\right)^{2}}{\sum_{i=1}^{k}\left(x_{i}+y_{i}\right) / 2-x_{i} y_{i}},
$$

where $x_{i}$ and $y_{i}$ are the frequencies of allele $i$ at the two sampling events and $k$ is the number of alleles at a locus. Data from multiple loci were combined by calculating the mean $\hat{F}_{\mathrm{c}}$, weighted by the number of alleles at each locus. We also calculated 95 per cent confidence intervals for each estimate of effective population size as suggested by Waples (1989). The estimates of effective population size are most easily interpreted when expressed as the ratio of effective population size to the census size, $N_{\mathrm{e}} / N_{\mathrm{c}}$.

\section{Effective size of island populations, $\mathrm{N}_{\text {e(i) }}$}

Species which are subdivided into local populations will have an effective population size different from a homogeneous population of similar size. For an island model of population structure the effective population size is actually increased by a factor $1 /\left(1-F_{\mathrm{ST}}\right)$ (Wright, 1943). There are several formulae developed for dealing with effective population sizes, but few can readily be extended to take population subdivision into account (Chesser et al., 1993; Whitlock \& Barton, 1997). Assuming that there is no territoriality in the studied species, one formula for the global effective population size of a subdivided population is given by:

$N_{\mathrm{e}(i)}=\frac{n \bar{N}_{\mathrm{e}(\mathrm{p})}}{\bar{N}_{\mathrm{e}(\mathrm{p})} F_{\mathrm{PL}}+\left(1+F_{\mathrm{IP}}\right)\left(1-F_{\mathrm{PL}}\right)}$,

where $n$ is the number of local populations and $\tilde{N}_{\mathrm{e}(\mathrm{p})}$ is the average effective size of the local populations (eqn 2) (Goudet, 1993). This formula is suitable when comparing the effective population sizes of two or more subdivided populations at different locations (Goudet, 1993).

\section{Results}

\section{Hierarchical population structure and gene flow}

Values for the hierarchical $F$-statistics for each locus and for all loci combined are presented in Table 1 . There are no indications of a general inbreeding effect at the lowest level in the hierarchy (within a tussock) because the combined estimate of $F_{\mathrm{IP}}$ is significantly smaller than zero (Table 1). This is anticipated in a dioecious, outbreeding organism, where the expected $F_{\text {IS }}$ value is $-1 /(2 d-1)$, where $d$ is the number of individuals sampled in a population (Kirby, 1975). The average number of individuals sampled per population was 8.1 , yielding a predicted $F_{\text {IS }}$ value of -0.066 . This value is of the same order as, but slightly larger in magnitude than, the combined estimate of $F_{\text {IS }}$ of -0.038 . The expected value of -0.066 also falls within the 95 per cent confidence interval calculated for the $F_{\mathrm{IP}}$ estimate (Table 1). It therefore seems clear that a single tussock constitutes the smallest randomly mating population of $P$. substriatus.

There is considerable variation among loci in the estimates of each $F$-statistic, but the combined estimate (over loci) showed significant differentiation at both the within- and between-island level. There is thus evidence for a hierarchical structuring of the genetic variation in $P$. substriatus. The degree of differentiation within islands is about three times that among islands $\left(F_{\mathrm{PL}}=0.043, F_{\mathrm{LT}}=0.013\right)$. When studying the different islands separately, it can be seen that there is a high degree of structuring among local $P$. substriatus populations within all islands, but the magnitude of the $F_{\mathrm{PL}}$ value differs among islands (Table 2). Islands 1 and 2 show about

Table 1 Hierarchical $F$-statistics for the five enzyme systems analysed in Phalacrus substriatus. Combined estimates and standard deviations were calculated by jackknifing over alleles and loci. $95 \%$ confidence intervals were obtained by bootstrapping. See text for further information

\begin{tabular}{lccrr}
\hline Locus & $F_{\mathrm{IP}}$ & $F_{\mathrm{PL}}$ & $F_{\mathrm{LT}}$ & $F_{\mathrm{IT}}$ \\
\hline$A c n$ & -0.042 & 0.050 & 0.024 & 0.033 \\
$I d h$ & -0.045 & 0.010 & 0.010 & -0.024 \\
$M d h$ & -0.083 & 0.054 & 0.002 & -0.022 \\
$P g i$ & -0.013 & 0.010 & 0.003 & 0.000 \\
$T p i$ & 0.037 & -0.061 & 0.004 & -0.018 \\
Combined & $-0.038^{*}$ & $0.043^{*}$ & $0.013^{*}$ & 0.020 \\
Jackknifed SD & 0.013 & 0.022 & 0.011 & 0.024 \\
95\% CI & -0.069 to -0.010 & 0.023 to 0.062 & 0.003 to 0.023 & -0.022 to 0.035 \\
\hline
\end{tabular}


the same degree of among-population differentiation $\left(F_{\mathrm{PL}}=0.029\right.$ and 0.026 , respectively), while island 3 shows much higher levels of differentiation $\left(F_{\mathrm{PL}}=0.077\right)$.

\section{Effective local population size}

Data on effective population size from 12 of the 15 tussocks sampled both in 1994 and 1995 are presented in Table 3, together with $N_{\mathrm{e}(\mathrm{p})} / N$ ratios. In the other three tussocks, the sample size was not large enough in both years to warrant an estimation of the effective population size. The $N_{\mathrm{e}(\mathrm{p})} / N$ ratio for all populations was substantially less than 1 , with a mean of 0.210 (geometric mean $=0.172$, range $0.042-0.491)$. This is well within the range of estimates for $N_{\mathrm{e}} / N$ ratios from other insect species (reviewed in Frankham, 1995). Because the sample

Table 2 Values of $F_{\mathrm{IP}}$ and $F_{\mathrm{PL}}$ for Phalacrus substriatus on a per island basis. Jackknifed standard deviations are shown in parentheses

\begin{tabular}{lcc}
\hline Island & $F_{\mathrm{IP}}$ & $F_{\mathrm{PL}}$ \\
\hline 1 & $-0.010(0.026)$ & $0.029(0.011)$ \\
2 & $-0.046(0.029)$ & $0.026(0.007)$ \\
3 & $-0.058(0.040)$ & $0.077(0.037)$ \\
\hline
\end{tabular}

sizes were generally small, the corresponding 95 per cent confidence intervals were large. However, in only one case did the 95 per cent confidence interval of the $N_{\mathrm{e}(\mathrm{p})} / N$ ratio exceed one (Table 3). The complete data set for the gene frequencies in the populations is available upon request from the authors.

\section{Effective island population size}

We calculated the average effective population size of the local populations on each island by taking the harmonic mean of the estimates of $N_{\mathrm{e}(\mathrm{p})}$ obtained above, for each island separately (Table 4). Using these values, together with the estimates of $F_{\mathrm{IP}}$ and $F_{\text {PL }}$, we calculated the $N_{\text {e(i) }}$ for each of the three islands included in the study using eqn (4) (Table 4). In each case, the calculated $N_{\text {e(i) }}$ value was slightly less that what would be expected of a similar, unstructured population $(n N)$ and even smaller than expected for an island model with constant population size and migration rate $\left(n N /\left[1-F_{\mathrm{ST}}\right]\right)$ (Wright, 1943).

\section{Discussion}

The area covered by the present study is fairly small (c. $0.25 \mathrm{~km}^{2}$ ), but the overall levels of differentiation are still quite high and comparable to studies of

Table 3 Estimates of the effective local population size, $N_{\mathrm{e}(\mathrm{p})}$, of Phalacrus substriatus. $S_{0}$ and $S_{1}$ are the sample sizes for the different sampling periods in 1994 and 1995 and $N_{\mathrm{c}}$ is the population size at the first sampling period (1994). $S_{0}$ and $N_{\mathrm{c}}$ differ as some individuals sampled could not be genotyped using the electrophoretic techniques. 95\% confidence intervals are also shown for each estimate. The numbers in column 1 refer to island and population, respectively, for instance 2:3 refers to population 3 on island 2

\begin{tabular}{lrrrrrrr}
\hline & & & & & \multicolumn{3}{c}{ Confidence intervals } \\
\cline { 5 - 8 } Population & $S_{0}$ & \multicolumn{1}{c}{$S_{1}$} & $N_{\mathrm{c}}$ & $N_{\mathrm{e}(\mathrm{p})}$ & Lower & Upper & $N_{\mathrm{e}(\mathrm{p})} / N_{\mathrm{c}}$ \\
\hline $1: 1$ & 12 & 9 & 12 & 5.89 & 1.32 & 62.60 & 0.491 \\
$1: 3$ & 25 & 16 & 26 & 6.97 & 1.22 & 9.78 & 0.268 \\
$1: 4$ & 17 & 6 & 18 & 0.76 & 0.23 & 1.86 & 0.042 \\
$2: 1$ & 15 & 28 & 15 & 2.72 & 0.98 & 5.32 & 0.181 \\
$2: 2$ & 23 & 17 & 23 & 3.53 & 1.02 & 9.82 & 0.153 \\
$2: 3$ & 21 & 17 & 21 & 4.80 & 2.01 & 7.91 & 0.229 \\
$2: 4$ & 19 & 22 & 21 & 2.06 & 0.51 & 3.97 & 0.098 \\
$3: 1$ & 17 & 17 & 21 & 4.85 & 1.32 & 15.23 & 0.231 \\
$3: 2$ & 7 & 6 & 7 & 1.68 & 0.46 & 5.30 & 0.240 \\
$3: 3$ & 14 & 19 & 15 & 2.01 & 0.77 & 7.23 & 0.134 \\
$3: 4$ & 31 & 26 & 32 & 9.79 & 3.01 & 14.89 & 0.306 \\
$3: 5$ & 24 & 30 & 25 & 3.58 & 1.44 & 8.45 & 0.143 \\
Mean & & & & & & & 0.210 \\
\hline
\end{tabular}


Table 4 The effective island population size, $N_{\mathrm{e}(\mathrm{i})}$, for Phalacrus substriatus estimated from eqn (4). The value is expressed as a ratio to the census size $\left(n N_{e(p)}\right)$

\begin{tabular}{lcccc}
\hline Number of & $\begin{array}{c}\text { Average local } \\
\text { local populations } \\
\text { sampled, } n\end{array}$ & $\begin{array}{c}\text { Island effective } \\
\text { population size } \\
\bar{N}_{\text {e(p) }}\end{array}$ & $\begin{array}{c}\text { population size } \\
N_{\text {e(i) }}\end{array}$ & $N_{\text {e(i) }} / n N_{\text {e(p) }}$ \\
\hline 1 & 41 & 1.84 & 68.5 & 0.92 \\
2 & 48 & 2.97 & 121.2 & 0.85 \\
3 & 40 & 2.98 & 89.7 & 0.75 \\
\hline
\end{tabular}

other, more mobile, insect species covering much larger areas (McCauley \& Eanes, 1987). The results from the hierarchical analysis further show that populations of $P$. substriatus are substructured at several different levels. The results are not surprising, given the short dispersal distances of individual P. substriatus beetles (average dispersal distance $c$. $0.9 \mathrm{~m}$; Ingvarsson et al., 1997). However, the differentiation among islands is only about one-third of that among local populations $\left(F_{\mathrm{LT}}=0.013\right.$ and $F_{\mathrm{PL}}=0.043$, respectively) and this stands in sharp contrast to the short dispersal distances of $P$. substriatus, which should imply extremely low levels of gene flow, and consequently high levels of differentiation, between islands.

Several explanations can be put forward to resolve this apparent contradiction. First, migration in natural populations of most organisms is highly stochastic, with large variation between years (Slatkin, 1985). When quantifying dispersal patterns of individual $P$. substriatus beetles using direct methods, we may have failed to observe the few events of long-distance dispersal that do indeed occur. Direct methods would consequently underestimate natural migration rates. Furthermore, longdistance dispersal events will have a disproportionately large influence on the among-island differentiation, even though they occur infrequently (Slatkin, 1985; Nichols \& Hewitt, 1994). Individual $P$. substriatus beetles are probably too small for active flight between islands and these beetles do not show any flight tendencies in either field or laboratory, even though they have fully developed wings (P. K. Ingvarsson, personal observation). There is, however, the possibility that some beetles are passively dispersed between islands. Phalacrus substriatus beetles have been found in drift material that is transported between different islands during periods when water levels are high (Palmén, 1944). This could result in long dispersal distances and would act to reduce differentiation among islands.
Secondly, assume that migration follows an island model of population structure and that an equilibrium between genetic drift and migration has been reached. The theoretically expected levels of differentiation among local populations and among islands are $F_{\mathrm{PL}} \approx 1 /\left(4 N_{\mathrm{e}(\mathrm{p})} m_{\mathrm{p}}+1\right)$ and $F_{\mathrm{LT}} \approx 1 /$ $\left(4 N_{\mathrm{e}(\mathrm{i})} m_{\mathrm{i}}+1\right)$, respectively (Slatkin \& Voelm, 1991). The denominators in these expressions are both a product of two independent parameters: the effective population size, $N_{\mathrm{e}}$, and migration rate, $m$ (with subscript $\mathrm{p}$ and $\mathrm{i}$ referring to population and island, respectively). Slatkin \& Voelm (1991) showed that if the migration rate among local populations is much larger than the migration rate among islands, an island can effectively be regarded as a single unit containing $n N_{e(p)}$ individuals (where $n$ is the number of local populations). Therefore, even if the migration rate among islands is perhaps one or two orders of magnitude lower than among populations, the larger effective island population size $\left(N_{\mathrm{e}(\mathrm{i})}\right)$ could compensate for the lower migration rate, yielding an apparently higher number of migrants moving among islands than among populations. This would, in turn, translate into lower levels of genetic differentiation among islands than among populations.

Lastly, population turnover can have a profound effect on the genetic differentiation of local populations (Slatkin, 1977; Wade \& McCauley, 1988). In the presence of frequent extinctions and recolonizations the result could be only a very weak correlation between the observed levels of differentiation and gene flow (Whitlock, 1992). If beetles colonizing a new island come from several source islands or if there are multiple, independent colonization events, a large proportion of the genetic variation present in the archipelago could be introduced to a new island (Slatkin, 1977, 1987). However, if local populations are small, genetic drift will tend to fix different alleles in different populations and will ultimately lead to an increase in the genetic differentiation among local populations on an island. The increase 
in genetic differentiation could be further enhanced if recurrent extinctions and recolonizations of local populations are frequent and especially if founders of new populations come from a limited number of sources (founders have a high probability of common origin, sensu Whitlock \& McCauley, 1990). In an earlier study (Ingvarsson et al., 1997) we have shown that local population turnover is common in $P$. substriatus and that founders of new populations indeed have a high probability of common origin because they come from only one or two source populations. We also showed that local extinctions and recolonizations result in an $\approx 40$ per cent increase in the degree of differentiation among populations on island 3 . These non-equilibrium dynamics can thus, to some extent, explain the high within-island levels of differentiation. However, there are reasons to believe that the rates of population turnover on islands 1 and 2 are much lower than on island 3 , simply because populations on those two islands are located further from the shoreline and therefore have a lower chance of being submerged during periods of high water ( $\mathrm{P}$. K. Ingvarsson, personal observation). Long periods with high water levels are the primary cause of extinctions of local populations of $P$. substriatus (Ingvarsson et al., 1997). This is thus consistent with the lower levels of genetic differentiation among populations observed on islands 1 and 2 (Table 2).

Greater genetic differentiation at local levels is uncommon, because differentiation is expected to increase with increasing distance among populations (Slatkin, 1985, 1987), although a few studies showing this pattern of differentiation can be found in the literature. Unruh (1990), studying patterns of genetic differentiation among 18 populations of the pear psylla, Cacopsylla pyricola, found that genetic variation was greatest among local populations within, as opposed to between, river drainages, something he attributed to nonequilibrium population processes resulting from pest management and to effects of the recent colonization of the American west coast by the pear psylla (Unruh, 1990). Costa \& Ross $(1993,1994)$ have performed one of the most comprehensive studies of the hierarchical population genetic structure of a single species in their study of the Eastern tent caterpillar, Malacosoma americanum, ranging from individual larval colonies on single trees to regional subpopulations covering a large proportion of the species range. For $M$. americanum there were no clear trends in the levels of differentiation with increasing distance among populations and the most pronounced genetic structuring actually occurred at the level of a single colony, because of kin associations among individual larvae in a colony (Costa \& Ross, 1993). Also, Johannesen \& Loeschcke (1996) studied four species of anthomyiid flies. In three of the species they found negligible degrees of differentiation among regions, whereas differentiation within regions was often quite high, something they attributed to both habitat history and specific gene flow patterns in the different fly species (Johannesen \& Loeschcke, 1996).

Recurrent extinctions and recolonizations will often reduce the global (island) effective population size (Whitlock \& Barton, 1997). Ingvarsson et al. (1997), using demographic data, found that population subdivision and turnover led to a reduction in the effective island population size by about 55 per cent on island 3. In this study, using eqn (4), we estimated $N_{\mathrm{e}(\mathrm{i})} / n N_{\mathrm{e}(\mathrm{p})}$ to be 75 per cent on the same island (Table 4). Ideally the two methods should yield the same result, but there are at least two reasons that can explain the higher estimate obtained in this study. First, the island-wide estimate of $N_{e(p)}$ (local effective population size) in this study is based on only five of the larger populations. This, in turn, influences the estimate of $N_{\mathrm{e}(\mathrm{i})}$ and will consequently lead to a rather imprecise estimate of $N_{\text {e(i) }}$. Secondly, eqn (4) does not explicitly take population turnover into account, which the method used by Ingvarsson et al. (1997) does. As frequent extinctions and recolonizations can greatly reduce the global effective population size and because turnover of local populations is a frequently occurring phenomenon in $P$. substriatus (at least on island 3; Ingvarsson et al., 1997), this will compromise the use of eqn (4) in determining $N_{\text {e(i) }}$. However, as we lack detailed demographic data from islands 1 and 2, the use of eqn (4) provides the only means by which we can obtain at least a crude estimate of the global effective population size for these two islands. The global effective population sizes on islands 1 and 2 are somewhat higher than on island 3 , which is to be expected if population turnover occurs at a lower rate on those two islands.

The results in this and a previous study (Ingvarsson et al., 1997) indicate that the population structure of $P$. substriatus is, to a very large extent, determined by the interplay of a number of random processes such as genetic drift, population turnover and gene flow, at least over the spatial scale of this study. The low effective population sizes, both at the population and island level, emphasize genetic drift as a major force in determining the local population structure of $P$. substriatus. It also implies that selection would have to be strong to overcome the 
combined effects of drift and migration to produce local adaptation in $P$. substriatus. Furthermore, it has been suggested in the literature that a subdivided population could maintain larger genetic variation than an unstructured population of similar size (Lacy, 1987). The rate of loss of genetic variation of such a population would also be lower than an unstructured population, because subdivision increases the global effective population size by a factor of $\left(1-F_{\mathrm{ST}}\right)$ (Wright, 1943). However, recurrent extinctions and recolonizations will, in most cases, lead to dramatic reductions in the effective population size and will consequently increase the rate at which variation is lost from the system (McCauley, 1991; Whitlock \& Barton, 1997). Thus, from a conservation point of view, failing to take processes such as extinctions and recolonizations into account can lead to highly erroneous results.

\section{Acknowledgements}

We would like to thank Barbara Giles, Jérôme Goudet and Michael Whitlock for stimulating discussions. Barbara Giles also read and commented on earlier versions of the manuscript. This study has been financially supported by grants from the Hierta-Rezius foundation (The Royal Swedish Academy of Sciences) and the Björkman foundation to P.K.I and grants from the Swedish Natural Science Research Council (NFR) to L. Ericson.

\section{References}

CHESSER, R. K., RHODES, O. E., SUGG, D. W. AND SCHNABEL, A. 1993. Effective sizes for subdivided populations. Genetics, 135, 1221-1232.

COSTA, J. T. AND Ross, K. G. 1993. Seasonal decline in intracolony genetic relatedness in eastern tent caterpillars: implications for social evolution. Behav. Ecol. Sociobiol., 32, 47-54.

COSTA, J. T. AND ROss, K. G. 1994. Hierachical genetic structure and gene flow in macrogeographic populations of the Eastern tent caterpillar (Malacosoma amer. icanum). Evolution, 48, 1158-1167.

Crow, J. F. AND KImura, M. 1970. An Introduction to Population Genetics Theory. Harper \& Row, New York.

ERICSON, I. 1981. Aspects of the shore vegetation of the Gulf of Bothnia. Wahlenbergia., 7, 45-60.

FRANKHAM, R. 1995. Effective population size/adult population size ratios in wildlife: a review. Genet. Res., 66 , 95-107.

GOUDET, J. 1993. The genetics of geographically structured populations. Ph.D. Thesis, University of Wales, Bangor. GOUDET, J. 1995. FSTAT v1.2. A computer program to calculate F-statistics. J. Hered., 86, 485-486.

INGVARSSON, P. K., OLSSON, K. AND ERICSON, L. 1997.
Extinction-recolonization dynamics in the mycophagous beetle Phalacrus substriatus. Evolution, 51, 187-195.

JOHANNESEN, J. AND LOESCHCKE, v. 1996. A hierarchical analysis of genetic structure and variability in patchily distributed coexisting Chiastochta species (Diptera: Anthomyiidae). Heredity, 76, 437-448.

KIRBY, G. C. 1975. Heterozygote frequencies in small subpopulations. Theor. Pop. Biol., 8, 31-48.

KOnTKanen, P. 1936. On the biology of Phalacrus substriatus. Ann. Entomol. Fenn., 2, 64-67.

LACY, R. C. 1987. Loss of genetic diversity from managed populations: interacting effects of drift, mutation, immigration, selection and population subdivision. Conserv. Biol., 1, 143-158.

McCAuley, D. E. 1991. Genetic consequences of local population extinction and recolonization. Trends Ecol. Evol., 6, 5-8.

McCAUlEY, D. E. AND EANES, W. F. 1987. Hierarchical population structure analysis of the milkweed beetle, Tetraopes tetraophthalmus (Forster). Heredity, 58, 193-201.

NEI, M. AND TAJIMA, F. 1981. Genetic drift and estimation of effective population size. Genetics, 98, 625--640.

NiCHOLS, R. A. AND HEwITT, G. M. 1994. The genetic consequences of long distance dispersal during colonization. Heredity, 72, 312-317.

NUNNEY, L. 1995. Measuring the ratio of effective population size to adult numbers using genetic and ecological data. Evolution, 49, 389-392.

PALMÉN, E. 1944. Die anemohydrochore Ausbreitung der Insekten als Zoogeographischer Faktor. Ann. Zool. Bot. Fenn., (Vanamo), 10, 1-259.

RODERICK, G. K. 1996. Geographic structure of insect populations: gene flow, phylogeography, and their uses. Ann. Rev. Ent., 41, 325-352.

SAS InSTITUTE 1NC. 1990. SAS/STAT User's Guide. Cary, NC.

SLATKIN, M. 1977. Gene flow and genetic drift in a species subject to frequent local extinctions. Theor. Pop. Biol., 12, 253-262.

Slatkin, M. 1985. Gene flow in natural populations. Ann. Rev. Ecol. Syst., 16, 393-430.

SLATKIN, M. 1987. Gene flow and the geographic structure of natural populations. Science, 236, 787-792.

SLATKIN, M. AND VOELM, L. 1991. $F_{S T}$ in a hierarchical island model. Genetics, 127, 627-629.

STEiner, W. E. J. 1984. A review of the biology of Phalacrid beetles (Coleoptera). In: Wheeler, Q. and Blackwell, M. (eds) Fungus-Insect Relationships. Perspectives in Ecology and Evolution, pp. 424-445. Columbia University Press, New York.

UNRUH, T. R. 1990. Genetic structure among 18 West Coast Pear psylla populations: implications for the evolution of resistance. Am. Entomol., 36, 37-43.

WADE, M. J. AND McCAUley, D. E. 1988. Extinction and recolonization: their effects on the genetic differentiation of local populations. Evolution, 42, 995-1005.

WAPLES, R. S. 1989. A generalized approach for estimating 
effective population size from temporal changes in allele frequency. Genetics, 121, 379-391.

weIR, B. S. 1990. Genetic Data Analysis. Sinauer Associates, Sunderland, MA.

WEIR, B. S. AND COCKERHAM, C. C. 1984 . Estimating $F$-statistics for the analysis of population structure. Evolution, 38, 1358-1370.

whITLOCK, M. C. 1992. Temporal fluctuations in demographic parameters and the genetic variance among populations. Evolution, 46, 608-615.
WHITLOCK, M. C. AND BARTON, N. H. 1997. The effective size of a subdivided population. Genetics, in press.

WHITLOCK, M. C. AND McCAULEY, D. E. 1990. Some population genetic consequences of colony formation and extinction: genetic correlations within founding groups. Evolution, 44, 1717-1724.

WRIGHT, s. 1943. Isolation by distance. Genetics, 28, 114-138.

WRIGHT, s. 1951. The genetical structure of populations. Ann. Eugen., 15, 323-354. 